\title{
Impuesto al Valor Agregado y pobreza en Colombia: 1999 - $2009^{1}$
}

\author{
Ruth Alejandra Patiño Jacinto ${ }^{2}$ \\ Orlando Darío Parra Jiménez $z^{3}$
}

Recibido: 15 de diciembre 2012

Aprobado: 15 de mayo de 2013

\begin{abstract}
Patiño, A. y Parra O. (2013). Impuesto al Valor Agregado y pobreza en Colombia: 1999 - 2009. Activos 20, 183-228
\end{abstract}

\section{Clasificación JEL}

H22, I32, P46

\section{Resumen}

El presente trabajo constituye una aproximación a la incidencia del Impuesto al Valor Agregado -IVA- en la evolución de los indicadores de pobreza en Colombia para el periodo comprendido entre 1999 y 2009. El documento inicia con una introducción al tema, en la segunda parte desarrolla los

1 Artículo derivado del proyecto de investigación desarrollado como opción de grado de la Maestría en Ciencias Económicas de la Universidad Santo Tomás.

2 Contadora Pública egresada de la Universidad Nacional de Colombia, Magíster en Ciencias Económicas de la Universidad Santo Tomás, Coordinadora del Centro de Investigaciones de la Facultad de Contaduría Pública de la Universidad Santo Tomás -CICOP-. Líder del grupo de investigación Contaduría: Información, control e impacto social y Directora del Observatorio Colombiano de Educación Contable OCEC. Correo electrónico: alejandrapatino@usantotomas.edu.co

3 Economista y Magíster en Ciencias Económicas de la Universidad Santo Tomás, Coordinador del Centro de Investigaciones de la Facultad de Negocios Internacionales de la Universidad Santo Tomás -CIFNI-. Correo electrónico: orlandoparra@usantotomas.edu.co 
conceptos básicos sobre la relación entre impuestos y pobreza, partiendo de la relación entre las decisiones de política en materia de impuestos y su posible impacto en las condiciones sociales de la población, específicamente en la pobreza.

En la tercera parte realiza un acercamiento a la medición de la pobreza, y finalmente una correlación entre los indicadores de pobreza y la evolución de la estructura del IVA en el periodo señalado, concluyendo que los cambios en el IVA contribuyeron a reducir los ingresos de la población, y así, a incrementar los índices de pobreza.

El análisis propuesto en el documento es relevante en la medida en que permite señalar la incidencia de la estructura tributaria y especialmente del impuesto al valor agregado en la dinámica del desarrollo social del país.

\title{
Palabras clave
}

Impuesto al Valor Agregado, progresividad, regresividad, pobreza

\author{
Patiño, A. y Parra O. (2013). Value Added Tax and poverty in \\ Colombia: 1999 - 2009. Activos 20, 183-228
}

\begin{abstract}
This work is an approach to assess the incidence of Value Added Tax -VATin the evolution of poverty indicators in Colombia for the period between 1999 and 2009. The paper begins with an introduction to the topic, in the second part; it develops the basic concepts about the relationship between taxes and poverty, based on the relationship between taxation policy decisions and its possible impact on the social conditions of the population, specifically on poverty.
\end{abstract}

The third part is an approach to the measurement of poverty and finally a correlation between poverty indicators and the evolution of the VAT 
structure within the given period, concluding that changes in VAT contributed to lower the population's incomes and thus increase poverty rates.

The analysis proposed in the document is relevant to the extent that it allows to point out the impact of the tax structure and especially of the value added tax on the dynamics of social development of the country.

\section{Keywords:}

Value Added Tax, progressivity, regressivity, poverty

Patiño, A. y Parra O. (2013). Taxe sur la Valeur Ajoutée (TVA) et la pauvreté en Colombie: 1999-2009. Activos 20, 183-228

\section{Résumé}

Le présent travail est une approximation de l'incidence de la Taxe sur la Valeur Ajoutée (TVA) dans l'évolution des indicateurs de la pauvreté en Colombie pour la période comprise entre 1999 et 2009. Ce document commence par une introduction du sujet, la deuxième partie développe les concepts de base sur la relation entre les impôts et la pauvreté, à partir de la relation entre les décisions politiques sur l'impôt et son impact potentiel sur les conditions sociales de la population, plus précisément sur la pauvreté.

Dans la troisième partie on fait une approche à la mesure de la pauvreté et finalement une corrélation entre les indicateurs de pauvreté et d'évolution de la structure de la TVA au cours de la période signalée, en concluant que les changements de TVA ont contribué à réduire le revenu de la population et ont ainsi augmenté les taux de pauvreté.

Lanalyse proposée dans le document est pertinente dans la mesure où elle permet de pointer l'incidence de la structure tributaire et en particulier de la Taxe sur la Valeur Ajoutée dans la dynamique du développement social du pays. 


\section{Mots clés:}

de Taxe sur la Valeur Ajoutée, progressivité, dégressivité, pauvreté

\section{Introducción}

La política económica es el estudio del conjunto de decisiones que toman diversos agentes, las cuales tienen como objetivo que la economía logre un estado aproximado al pleno empleo, estabilidad en el nivel de precios, mejoras en las condiciones macroeconómicas, entre otros objetivos que se orientan a alcanzar el desarrollo y bienestar de la población.

Dentro de la política económica, se encuentran inmersas tres clases de decisiones: monetarias, fiscales y cambiarias. El análisis en este documento se centrará en la segunda dimensión: la política fiscal, la cual se refiere al estudio de la consecución de recursos fiscales orientados a subsanar o cubrir los gastos estatales (Hernández, 2005).

Un aspecto fundamental de la política fiscal es la evaluación del impacto de las alternativas de financiación, dado que de la asignación de éstas depende el cumplimiento de algunos de los objetivos del Estado. De acuerdo con Musgrave (1992), las funciones que cumple la política fiscal son: asignación, distribución y estabilización económica.

El problema en el que se ha centrado en los últimos años la preocupación de los Estados es la prioridad del combate de la pobreza, mediante la transferencia total o parcial de las tareas sociales estatales a actores privados o a entes regionales y locales. La reorientación conceptual de la política pública tiene una importante dimensión política, así como repercusiones significativas en términos de estrategia de desarrollo. En efecto, mientras los conceptos de:

Compensación, focalización y combate de la pobreza contribuyen a redefinir la actividad estatal en el ámbito del desarrollo social, los enfoques privatizadores y descentralizadores afectan la definición de las esferas de 
lo privado y lo público; asimismo, redistribuyen competencias y recursos entre el Estado central y otros actores sociales (Sottoli, 2002, p. 44).

A partir de los años noventa, con los fenómenos de apertura económica se generaron efectos inmediatos en la regulación estatal como la disminución de aranceles, el debilitamiento de muchos sectores económicos y, como consecuencia de ello, la necesidad creciente del Estado por generar ingresos que reemplazarán lo perdido por la rebaja generalizada de aranceles. Esto llevó en Colombia a un cambio en la estructura tributaria, la cual, en los últimos veinte años, ha estado basada cada vez más en impuestos indirectos.

En los últimos veinte años, la estructura impositiva tuvo un cambio radical: los tributos de carácter interno cobraron cada vez mayor importancia. Hubo un cambio en la composición de los ingresos tributarios, especialmente en el IVA, ya que las modificaciones en la tasa y base del impuesto lo convirtieron en la mayor fuente de recursos tributarios de la Nación, adquiriendo la misma importancia en términos de recaudo que el impuesto de renta.

"El IVA pasó de representar el $29 \%$ del recaudo en 1990 a representar el 40 \% de los ingresos tributarios para el 2002" (González y Calderón, 2002, p. 20). El Impuesto al Valor Agregado fue el tributo que más se modificó durante el curso de la década de los noventa; sin embargo, estos cambios estuvieron dirigidos principalmente a modificar la tarifa de impuesto sin grandes cambios sobre la base del mismo. En 1990 se aumenta por primera vez la tarifa del IVA, de $10 \%$ a $12 \%$ y se amplía la base; de nuevo, en 1992, la tarifa pasa de $12 \%$ a $14 \%$, "elevando hasta $45 \%$ las tarifas para bienes de lujo. El impuesto entonces se convierte en un impuesto al consumo, evitando así el efecto cascada, es decir, que fuese cobrado más de una vez en la cadena de producción" (Steiner y Soto, 1998, p. 2).

Si se toman como base los datos de recaudo de la DIAN, el IVA representaba el 31,63\% de los impuestos nacionales, el 43,01 \% en 1999 y el $40.70 \%$ para el año 2009. Esta evolución de comportamiento está reflejada en la Gráfica 1. 
Gráfica 1. Recaudo del IVA como porcentaje del total de los impuestos nacionales, 1990 - 2009

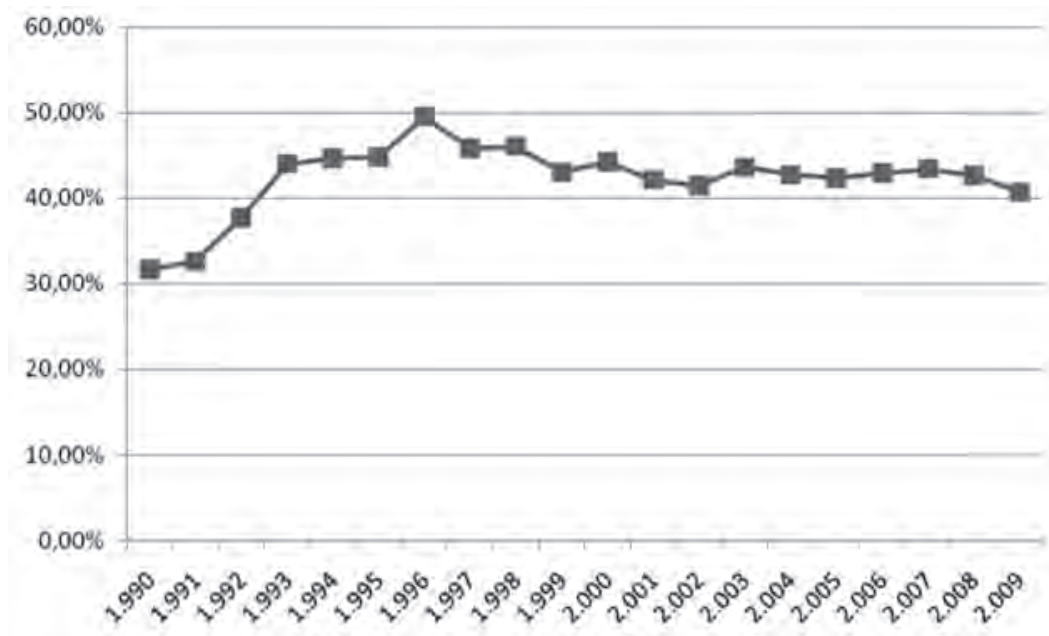

Fuente: elaboración autores basada en los datos suministrados por la DIAN (tabla de datos suministrada como Anexo No. 1).

Con la reforma tributaria de 1996, la tarifa del impuesto pasa de $14 \%$ a $16 \%$, y de nuevo se hacen esfuerzos para ampliar su base. En 1999 la tarifa pasa de $16 \%$ a $15 \%$, como había sido el propósito de campaña del expresidente Andrés Pastrana. Sin embargo, el mismo gobierno, y gracias a las fuertes presiones sobre los ingresos, debe restablecer la tarifa del impuesto en $16 \%$ con la reforma tributaria de 2000 , con el objetivo de compensar la caída de los ingresos tributarios generada por el desmonte de las restricciones al comercio exterior.

En este aspecto la discusión gira alrededor de la conveniencia de incrementar los impuestos indirectos y obtener recursos fiscales frescos, o cumplir con los principios de equidad y progresividad; en Colombia, la tendencia ha sido incrementar el recaudo por impuestos indirectos, con el fin de subsanar lo que se dejó de percibir por la disminución de los aranceles, ya que al incrementar la tributación indirecta, especialmente el IVA, no se 
tiene en cuenta la capacidad de pago de las personas o sujetos del tributo, de manera que terminan pagando proporcionalmente más impuestos quienes tienen ingresos proporcionalmente más bajos, afectando negativamente la equidad y aumentando la brecha de pobreza. La estructura tributaria resulta ser regresiva.

Las decisiones de política fiscal influyen sobre el bienestar de la población; dicha política puede ser expansiva a través de una disminución de impuestos o un aumento del gasto público junto con el consecuente aumento de la demanda agregada, la expansión del consumo y el empleo. Por el contrario, una política contractiva presenta efectos sociales cuestionables. En el caso específico del IVA, su evolución podría generar impacto en la pobreza (equidad y progresividad) y en las decisiones de política fiscal del gobierno. Con el fin de establecer dicho impacto, se analizarán el comportamiento del IVA y su incidencia en la pobreza entre 1999 y 2009 en Colombia.

En el primer capítulo se desarrollan conceptos generales alrededor de las temáticas de impuestos y pobreza, en el segundo capítulo se muestran las principales formas de medición de la pobreza, posteriormente en el capítulo tres se realiza una caracterización del IVA, el trabajo culmina con una relación entre el IVA y la pobreza en Colombia en el periodo en mención a partir del desarrollo de un modelo econométrico, con el cual se pretende concluir acerca de la incidencia de dicho impuesto sobre la pobreza en Colombia.

\section{Conceptos generales}

\subsection{Conceptos básicos relacionados con el tema de impuestos}

Un impuesto, básicamente, es un pago obligatorio al Estado que no presenta contraprestación, o que no es explícita. De acuerdo con Giraldo, "los impuestos se pagan de acuerdo con el patrimonio o las rentas que recibe el ciudadano (impuestos directos), o con el valor de la transacción económica 
que realiza (impuestos indirectos)" (2001, p. 119); en esta última clase se encuentra el IVA.

Los supuestos de la economía neoclásica indican que los impuestos se recaudan para proveer bienes y servicios que están por fuera del ámbito de provisión del mercado, es aquí donde surge el concepto de bien público y bien privado. Los bienes privados son aquellos que le pertenecen a una persona en particular. En este caso se dice que la persona tiene derechos de propiedad sobre ellos; por otro lado, los bienes públicos son aquellos que pertenecen a todos y no a alguien en particular.

Un bien público puro es aquel que es no rival y no excluyente, es decir, un bien es no rival cuando el uso de éste por una persona en particular no perjudica al resto de personas, y no excluyente quiere decir que todos deben disfrutar de este bien, o sea que no se puede excluir a nadie de usarlo o tenerlo, además los bienes públicos puros tienen dos características esenciales, la primera que no es viable racionar su uso y segundo, no es deseable racionarlo.

La inviabilidad de un sistema de racionamiento basado en los precios implica que el mercado competitivo no genera una cantidad del bien público eficiente en el sentido de Pareto ${ }^{4}$. El gobierno entonces debe proveer este bien, financiándolo mediante impuestos.

Todo el marco conceptual sobre el cual se basan las finanzas públicas en Colombia, y en general en América Latina, se basa en seis políticas con el fin de promover la vigencia del mercado y la mínima intervención del Estado. Estas políticas, de acuerdo con Giraldo (2001), son:

1. Desregulación de la economía, lo cual implica desmonte de controles y reglas administrativas, ya que de acuerdo con el paradigma neoclásico, esto entorpece el libre funcionamiento del mercado.

4 Situación en la cual un mejoramiento para un agente económico implica desmejorar las condiciones de otro u otros. 
2. Eliminación de los subsidios a la oferta y el establecimiento de los subsidios a la demanda.

3. La provisión de bienes y servicios estatales puede ser asumida por el sector privado, lo que implica que la participación del Estado en estos aspectos genera una intervención excesiva. En esto se ve el impulso dado a procesos de privatización.

4. En materia de tributación, se privilegia el principio de neutralidad, es decir, los impuestos deben producir las menores distorsiones posibles.

5. Se utiliza la descentralización como mecanismo para introducir competencia entre las regiones, y además acerca al usuario y al prestador del servicio.

6. Se busca continuamente el equilibrio fiscal, dado que el enfoque es neoclásico, basado en el equilibrio general.

En los principios tributarios aplicados actualmente, es evidente el paradigma de la economía neoclásica actual, el cual se basa en el libre funcionamiento del mercado, es así como se le da prioridad a la neutralidad, es decir, todo impuesto debe ser neutral en la economía y no incidir en su comportamiento. Giraldo afirma: "el concepto de neutralidad está asociado con el de eficiencia, resultado ésta de la asignación de recursos a través del mercado" (2001, p. 122). Se hace especial énfasis en que la tributación no debe incidir en las decisiones de tipo económico, esto es llamado eficiencia, es decir, que un impuesto es eficiente en términos de mercado cuando no introduce distorsiones en el mismo.

Por otro lado, se requiere que el sistema tributario no sea complejo, ya que esto incentiva la evasión y va en contravía del objetivo estatal de recaudar la mayor cantidad de impuestos posibles, es decir, debe ser un sistema tributario que propenda por la simplicidad y, adicionalmente, esto implica gravar la generalidad y evitar las exenciones. De lo anterior se desprende otro principio, la flexibilidad, la cual se presenta cuando los impuestos no tienen destinación específica y de esta forma el gobierno puede decidir sobre qué gastos utilizar este tipo de ingresos y cambiar los mismos de acuerdo con los cambios en el entorno (Giraldo, 2001). 
Existen otros principios tributarios, que no presentan relación directa con el modelo económico vigente, como por ejemplo la progresividad, la cual hace referencia al reparto de la carga tributaria entre los diferentes agentes obligados a su pago, según la capacidad contributiva de la que disponen, es decir, es un criterio de análisis de la proporción del aporte total de cada contribuyente en relación con su capacidad contributiva. En esa misma medida, una dimensión más amplia del principio de progresividad del sistema es la que valora el destino y los efectos del gasto público financiado con los recursos recaudados. En este sentido, es relevante su impacto en la situación relativa de los contribuyentes y, en general, de los habitantes de un país. La neutralidad, progresividad o regresividad del sistema en esta perspectiva más amplia se apreciaría comparando las condiciones económicas de los diferentes integrantes de la sociedad después de efectuado el gasto público.

La equidad es otro principio que ha aparecido por la preocupación de tipo social, presente en muchos de los hechos de tipo político y económico del país, "se puede tratar desde dos ángulos: tratamiento igual para los iguales (equidad horizontal) y diferente para los diferentes (equidad vertical)” (Giraldo, 2001, p. 124). Dicho principio está asociado con la progresividad, ya que de acuerdo con Silva, un impuesto progresivo es aquel en que la carga impositiva es más alta en la medida en que se gana más, mientras que en los impuestos regresivos dicha tarifa es más alta en la medida en que se gana menos (2008, p.3), lo cual conduce a deducir que los impuestos regresivos también conducen a inequidad, ya que grava en mayor medida a los que tienen condiciones menos favorables, lo cual, de acuerdo con Clavijo (2005), se plantea como la necesidad de balancear de mejor manera los gravámenes sobre las empresas, las personas naturales y la tributación indirecta que provee el IVA.

\subsection{Aproximación a los conceptos de pobreza y la definición de los impuestos en los principales economistas clásicos y posteriores}

Inicialmente, los mercantilistas planteaban la necesidad del aumento de la riqueza por medio del comercio internacional, ya que se tomaba como un 
valor fijo, es decir, si una Nación aumentaba su riqueza, necesariamente era que otra la había disminuido. En términos de pobreza se plantea que "la pobreza del individuo beneficia la Nación, cuando la meta de la actividad económica se define en función del producto nacional y no en términos del consumo nacional" (Landreth, 1998, p. 37). Es así como la pobreza de las personas no es preocupación para esta teoría naciente, y en términos de impuestos la preocupación fundamental va encaminada a incentivar el comercio exterior y no el consumo, ya que éste requiere gastos y, por ende, empobrecimiento de la Nación.

Los mercantilistas difieren de los fisiócratas sobre la cuestión tributaria en términos de que

Los fisiócratas afirmaban que los principales obstáculos para el crecimiento económico provenían de las políticas mercantilistas que regulaban el comercio interior y exterior. En particular, objetaban el sistema de impuestos de los mercantilistas y argumentaban que se estableciera un solo impuesto sobre la tierra (Landreth, 1998, p. 54).

Una de las preocupaciones de William Petty (1623-1687) fueron los impuestos, solo que desde la perspectiva económica, es decir, cómo los tributos afectaban la dinámica económica, sin tener en cuenta las consecuencias sociales de los mismos, en este sentido Petty

Está de acuerdo con Mun en considerar inevitables los impuestos... aunque pueden verse obligados a recaudar por la vía de impuestos más de lo que necesitan, a fin de crear una reserva para casos de emergencia, no deben hacerlo con demasiada frecuencia, porque retirarían dinero de sus súbditos de la circulación productiva... Petty pedía economías en el funcionamiento de los principales servicios del Estado: defensa nacional, administración pública, justicia y "pastoreo de almas de los hombres" (Roll, 1994, p. 95).

Es evidente que la postura frente al papel del Estado en Petty va encaminada a las funciones básicas y las preocupaciones por aspectos sociales, específicamente en el tema de pobreza, aún están ausentes en este autor. 
En el tema de tributación y pobreza, se debe hacer referencia a la teoría clásica económica (Smith y Ricardo), donde trabajaron estos conceptos enmarcados dentro de la explicación del comportamiento de los individuos frente a las necesidades y bajo la premisa de la "mano invisible".

De acuerdo con los llamados economistas clásicos, el papel del Estado debe estar limitado a brindar las condiciones básicas que aseguren el comportamiento libre de los agentes económicos en el mercado, es así como los conceptos de pobreza, ingreso e impuestos quedan ligados de manera implícita al desarrollo de los aspectos que incluyen los clásicos de trabajo, producción, ingreso, libre mercado, donde cualquier daño de manera directa al ingreso, genera distorsión al concepto de "mano invisible". Por lo tanto, la pobreza se define como un resultado del proceso económico (la diferencia entre los dueños de los factores de producción y quienes deben vender su mano de obra para subsistir) y es obligación de la población superar este estado para lograr su plenitud económica.

Un factor para resaltar, de acuerdo con Silva, es que: "Adam Smith señaló en el siglo XVIII, en su obra "La Riqueza de las Naciones", que una de las cuatro máximas que debe guardar cada uno de los impuestos que forman parte de un sistema tributario -y en nuestra opinión, el más importante-, es la capacidad de pago del obligado o proporcionalidad" (2008, p. 2). Esto muestra que si bien la tendencia era hacia una economía de mercado con un Estado no intervencionista, se tenía en cuenta la proporcionalidad del impuesto, es decir, se deben evitar excesos sobre los pagos de los mismos y consultar la capacidad de pago.

En este sentido, David Ricardo plantea que

Los impuestos son una porción del producto de la tierra y de la mano de obra de un país, puestos a disposición del gobierno; su pago proviene siempre, en último término, ya sea del capital o del ingreso del país (Ricardo, 1993, p. 114). 
Esta visión es compartida con Smith, el cómo los impuestos afectan el funcionamiento de las economías y las decisiones de producción.

A pesar de pertenecer a generaciones diferentes, Smith y Ricardo se preocuparon por el tema de la pobreza porque fue uno, si no el mayor, de los problemas sociales enfrentados por la Inglaterra de los siglos XVIII y XIX (Pardo, 2000, p. 112).

De tal forma que los principales pilares teóricos de la economía clásica lograron combinar la teoría con preocupaciones acerca de este tema, los cuales se evidencian principalmente en "La teoría de los sentimientos morales" de Smith.

Por su parte, Karl Marx no menciona el término pobreza; sin embargo, en su obra la diferencia de las clases sociales está dada en términos de que algunos no tienen medios de producción, los cuales son necesarios para la generación de nuevo valor y, por ende, para subsistir y acumular capital; es importante resaltar que toma en cuenta que no solo es necesario contar con los medios para empezar a producir, sino que debe poseer una base inicial de subsistencia mientras el proceso productivo presenta resultados, es así como se generan diferencias marcadas entre los sectores de la población:

El antiguo poseedor de dinero abre la marcha convertido en capitalista, y tras él viene el poseedor de la fuerza de trabajo, transformado en obrero suyo (Marx, 1946, p. 129).

El ingreso está dado por el salario, éste se entiende como el resultado de un proceso en el cual

Las personas que no son dueñas de los procesos de producción, sino de la fuerza de trabajo, se ven obligadas a vender su trabajo para poder sobrevivir y así acceder a los bienes producidos por el mercado (Pesenti, 1960, p. 132).

Entonces, el salario es el determinante del comportamiento de la población. Cuando éste se fija dentro de los límites de subsistencia de la 
clase trabajadora, y hay un aumento de la producción, la población crece aumentando la oferta y generando un crecimiento natural. Quien esté por debajo del límite de subsistencia será considerado en estado de pobreza. Es aquí donde aparece el primer concepto de pobreza ligado al nivel de ingresos de la clase trabajadora, si el individuo no puede salir de ese estado entonces es el gobierno quien se debe preocupar por brindar las condiciones básicas para sostener al individuo y que sea productivo para el sistema económico.

El sistema capitalista se fundamenta sobre un hecho social: el mercado como la fuente básica para la existencia de ganancias, el diferencial entre los ingresos y utilidades donde cualquier alteración a la estabilidad económica genera crisis en el sistema, la interrupción o alteración del proceso resulta en lo que se llama ciclos económicos y es en los ciclos de depresión donde el gobierno debe intervenir para asegurar la continuidad del mercado. Es en este ciclo donde se reducen las inversiones, se disminuye la demanda y la producción, se despiden obreros, se niegan aumentos salariales y se genera sobreproducción.

Keynes no compartía la idea de que una economía de mercado conduce automáticamente al pleno empleo, sino que abre la puerta a la necesidad de la política económica, es decir, a la intervención del Estado para alcanzar una situación adecuada. En este modelo queda en entredicho el funcionamiento del libre mercado para alcanzar el equilibrio de la economía; dicho autor supuso que la inflexibilidad a la baja de los salarios monetarios impide el ajuste automático de la economía. La única forma de aumentar el nivel de empleo con objeto de incrementar la demanda es a través del multiplicador del gasto del gobierno. La relación entre crecimiento demográfico y expansión económica es el interés de este modelo, ya que el aumento demasiado rápido de la población conduciría a la trampa malthusiana ${ }^{5}$ como el estancamiento, que llevaría a la quiebra de la demanda efectiva (desempleo). Keynes situó el problema económico en la utilización de los recursos como el capital físico y humano, en donde las políticas macro-

5 Entendida como el crecimiento desmedido de la población y la escasez de los recursos. 
económicas debían planificar el desarrollo de las sociedades con el fin de mejorar el uso de dichos recursos.

Posteriormente, aparece el modelo de crecimiento económico fundamentado en la estructuración de los modelos neoclásicos, los cuales trabajan el incremento del ingreso per cápita, cuyo objetivo principal era la acumulación de capital, dando así origen al concepto de inversión de capital humano, el cual implica la aceleración del crecimiento y desarrollo económico. Pero cuando esta acumulación es insostenible en el largo plazo se genera entonces pobreza, es donde el Estado y el gasto público desempeñan un papel fundamental, ya que las metas más comunes del gobierno son incrementar el ingreso per cápita de la población, distribuir el ingreso nacional de forma más equitativa, a tenor del ingreso derivado de las variaciones del mercado, y eliminar el desempleo (González, 1968).

Es función de la política fiscal aumentar la tasa de ahorro e inversión, ampliar la capacidad productiva y generar empleo evitando la inflación, la inversión pública favorece la infraestructura económica y social (González, 1968, p. 21).

La política fiscal logra aumentar el porcentaje de ahorro y de la inversión en relación con el ingreso nacional. Es aquí donde surge la tributación o fuente de financiamiento de la política fiscal. Tributar según la capacidad de pago, gravar con el mismo porcentaje los ingresos de las personas de elevados ingresos y de bajos ingresos, impondrían sacrificios desiguales sobre todo a los últimos, ya que sentirían una mayor reducción de sus ingresos.

Un aspecto que impulsó la discusión del concepto de pobreza fue el desarrollo de una teoría sobre sus orígenes en el seno de las economías de mercado, a partir de los trabajos de Schumpeter se incorporan nuevos aspectos en el concepto de pobreza, lo cual ya le permitía señalar que

A la importancia otorgada al crecimiento sucedió una preocupación por los objetivos propiamente dichos del desarrollo, esto es, por los fines (la 
mejora en la calidad de vida de la población) y no tanto por los medios (la expansión de la renta per cápita" (Bustelo, 1999: 143).

En el anterior contexto surgen distintas preocupaciones como la distribución del ingreso, el empleo y la pobreza, las cuales posteriormente serían el centro del debate económico y lograrían un auge gracias al desarrollo de los trabajos de Amartya Sen.

\subsection{El concepto de pobreza}

La pobreza como concepto puede entenderse como la condición en la que una población no logra acceder a la mayoría de los beneficios establecidos para el conjunto de la sociedad en la que vive. En realidad, esto genera exclusión social, en términos en los que la población se encuentra en condición de carencia respecto al acceso a bienes y servicios básicos de la sociedad.

Según el Banco Mundial,

se presenta pobreza cuando no se alcanza el mínimo de bienes que debe tener una persona o grupo para encontrarse en una situación digna de vida. Es el gobierno quien debe solucionar los problemas de estas necesidades con provisión de bienes públicos (2001, p. 5).

Posteriormente a este concepto se desarrolló un enfoque más amplio, basado en la noción de las necesidades básicas como criterio para juzgar las dimensiones y situaciones de pobreza. De acuerdo con Bustelo, "las necesidades básicas fueron definidas entonces por la OIT como las que aseguraban un nivel de vida mínimo que toda sociedad debería establecerse para los grupos más pobres de sus habitantes" (1999, p. 152).

Este enfoque materializa una forma de establecer las dimensiones de la pobreza de un determinado sector de la población, es aquí donde surge la concepción más básica y en 1975 se establecen cuatro aspectos fundamentales: 
- El consumo alimentario, la vivienda y el vestido.

- El acceso a servicios públicos de educación, sanidad, transporte, agua potable y alcantarillado.

- La posibilidad de un empleo adecuadamente remunerado.

- El derecho a participar en las decisiones que afectan a la forma de vida de la gente y a vivir en un medio ambiente sano, humano y satisfactorio (Bustelo, 1999, p. 153).

La discusión actual sobre la pobreza va mucho más allá de la tradicional visión sobre los bienes materiales, si bien estos son determinantes en cualquier diagnóstico sobre su naturaleza y, por ende, de las políticas de asignación de recursos a seguir por un gobierno.

Desde el punto de vista económico, la definición de pobreza se puede desarrollar a partir de diferentes criterios, así:

Para Atkinson, la pobreza es el resultado de la inequitativa distribución del ingreso, el obstáculo a los individuos para acceder a recursos o la falta de ingresos que genera brechas entre los niveles de vida entre las personas o la comunidad. Citado por Serrano (2001, p. 4).

Y en una dimensión algo diferente

Para Sen, la pobreza se concentra en la ausencia de capacidades de los individuos y sus posibilidades de desarrollar habilidades y allí lo material pasa a un segundo plano, sin dejar de ser importante, permite analizar cómo las estructuras sociales permiten a los individuos acceder a un bien (Serrano, 2001, p. 6).

El elemento común de las anteriores definiciones determinan la pobreza como la ausencia de al menos un factor de los indicados, lo cual genera una posición económica que se encuentra ligada con la desigualdad, donde los recursos del consumo son un indicador del concepto de pobreza. En este sentido, Max Weber enuncia que las categorías económicas son las que relacionan y establecen las condiciones de exclusión o dependencia. 
En Colombia, los trabajos sobre pobreza tienen una historia reciente; solo a mediados de los años ochenta se inició un trabajo sistemático que permitiera generar información con el uso de teorías sobre la dimensión de la pobreza. El concepto de pobreza en Colombia es bastante amplio, ya que incluye una serie de elementos de tipo cultural, educativo, económico y étnico, en el cual esta dimensión es parcial y varía según los grupos sociales.

De acuerdo con Ortiz, Ortiz \& Cárdenas (2004, p. 3), la pobreza puede analizarse a través de tres elementos:

- Biológico o de subsistencia: Toma en cuenta las mínimas condiciones biológicas que permiten la supervivencia del individuo.

- Necesidades básicas: Incluye dos aspectos, i) los requerimientos mínimos del consumo de una familia y ii) los elementos dimensionales que garantizan el acceso al ingreso.

- Privación relativa: relación cambiante entre la privación y el ingreso en el curso del tiempo y en las distintas sociedades, por esto es relativa porque depende de la concepción de cada sociedad frente a las necesidades y sus consecuentes privaciones.

La Tabla 1 hace una presentación sintética acerca de todos los conceptos de pobreza.

Tabla 1. Síntesis de definiciones de pobreza

Perspectiva: ausencia de recursos/privación.

Escuela: neoclásica (esta escuela recoge la mayoría de modernas interpretaciones sobre el concepto de pobreza).

Visión: materialista/utilitarista, procedimentalista.

Características básicas: falta de un recurso o recursos ante un referente de dotación de recursos que posee un individuo, grupo o comunidad que presenta un grado de bienestar. Como consecuencia de esta privación, se presenta una pérdida de bienestar. En el modelo neoclásico se asume equidad en la dotación inicial de un individuo o familia, éste es un fuerte supuesto del modelo. 
Perspectiva: insuficiencia de medios para adquirir recursos.

Autores: Atkinson, Bourguignon.

Visión: inequidad social/consecuencialista.

Características básicas: inequitativa distribución del ingreso que genera un obstáculo a los individuos para acceder a recursos, o falta de ingresos que genera brechas entre niveles de vida entre las personas. Nivel mínimo de vida razonable frente a los estándares de la sociedad.

Perspectiva: necesidades básicas (privación).

Escuela/autores: Banco Mundial.

Visión: materialista/procedimentalista.

Características básicas: mínimo de bienes que debe tener una persona o grupo para encontrarse en una situación digna de vida. Pérdida de bienestar por tal circunstancia. Existe quien puede solucionar los problemas de necesidades con provisión de bienes públicos.

Perspectiva: problema de capacidades individuales/titularidades.

Autores: Sen, Dréze.

Visión: individualismo/liberalismo.

Características básicas: se concentra en las capacidades de los individuos y en su posibilidad de desarrollar habilidades, allí lo material pasa a un segundo plano (sin dejar de ser importante). Las titularidades permiten analizar cómo las estructuras sociales le permiten a los individuos acceder a un bien. Cualquier desigualdad en la estructura social genera un problema.

Perspectiva: clase social/desigualdad.

Escuela: marxista.

Visión: explotación/socialismo.

Características básicas: la extracción social genera grandes desigualdades entre los grupos sociales, los cuales explican su bajo nivel de bienestar. Apropiación de un grupo de clase del excedente que otros producen. Problemas de estructura social. Dificultades en los accesos a bienes de posición.

Perspectiva: problema moral.

Visión: ética.

Características básicas: posición normativa frente a la pobreza en planos de carácter cultural.

Fuente: (Serrano, 2001, p. 2). 


\section{Medición de la pobreza}

La medición de la pobreza como fenómeno económico es fundamental en la toma de decisiones de política pública. Los hogares son considerados como la base primaria de la sociedad y es sobre ellos que se trazan las principales mediciones de pobreza. A este respecto, algunas de las metodologías usadas en Colombia son: necesidades básicas insatisfechas y línea de pobreza.

La primera, que expresa las características físicas y las necesidades consideradas indispensables en un hogar moderno, trabaja cinco indicadores: indicador de vivienda inadecuada, indicador de servicios públicos inadecuados, hacinamiento crítico, inasistencia escolar, dependencia económica. El criterio de decisión es que un hogar está en pobreza absoluta si presenta alguna de estas situaciones y en miseria si presenta dos o más de estas situaciones (Serrano, 2001).

La medición por línea de pobreza plantea un indicador que mide los ingresos y la distribución de estos entre los hogares, los criterios y supuestos que se tienen en cuenta para este indicador son: 1 . El ingreso corriente como indicador adecuado de la norma de vivir de los individuos. 2. Cada individuo en la casa tiene las mismas necesidades. 3. No hay ninguna economía de escala en el consumo. 4. El error estadístico en estudios del hogar es pequeño y el ingreso o consumo medio en estos trabajos es una medida adecuada.

El indicador establece si los hogares tienen ingresos suficientes para obtener los bienes y servicios necesarios para satisfacer el consumo de una canasta normativa; dicha canasta básica de bienes y servicios cumple requisitos de satisfacción de necesidades; el costo de la misma está definido por los precios de mercado; el criterio de decisión es que si el ingreso del hogar está por debajo del costo de la canasta normativa, éste se define como un hogar pobre.

Para Lustig et al (2000) -citado por Serrano (2001)-, así como para la Misión para la Reducción de la Pobreza y la Desigualdad, MERPD 
(2006)-citado por Núñez (2009) - en las mediciones de la línea de pobreza se realiza la construcción de canastas normativas que cumplen dos condiciones básicas: i) satisfacen las necesidades nutricionales de un colombiano promedio; ii) presentan el mínimo costo posible.

La línea de indigencia (LI) se calcula como el valor de la canasta normativa de alimentos, y la línea de pobreza (LP) se obtiene de multiplicar la LI por el inverso del coeficiente de Engel ${ }^{6}$, medida que también es conocida como el coeficiente de Orshansky.

Los indicadores de necesidades básicas insatisfechas y pobreza están bajo la influencia de la teoría de la utilidad neoclásica, en la cual los agentes económicos maximizan su función de utilidad a través del consumo de una canasta de bienes; lo que se cuestiona en este modelo es si efectivamente la utilidad es un elemento que permite definir el nivel de vida de las personas (Serrano, 2001).

Para suplir las deficiencias de estos indicadores, se han creado otras medidas que pretenden corregir estas limitaciones, entre ellas se encuentra el denominado índice de Sen, el cual maneja tres aspectos de la pobreza: magnitud, porcentaje de pobres para una línea de pobreza definida y la distribución del ingreso entre los pobres, medidos por el índice de Gini.

El índice de Sen varía entre 0 y 1; cuando ingrese a la población pobre es homogéneo, el índice de Gini es 0 . El índice de Sen mide la intensidad de la pobreza ponderando la brecha de pobreza de cada grupo por su brecha respectiva para determinar la pobreza total (Nina y Aguilar, 1998, citado por Serrano (2001).

De acuerdo con los parámetros considerados, la evolución reciente de la pobreza en Colombia es como se presenta en la Tabla 2.

6 De acuerdo con Núñez (2009), se calcula como el porcentaje que tienen los alimentos en el gasto total que realiza la población de referencia. 
Tabla 2. Índice de Sen Colombia 2009

\begin{tabular}{lc}
\hline Parámetro & Valor a 2009 \\
Magnitud de pobres & 20.000 .000 \\
Porcentaje de pobres a partir de línea de pobreza $^{1}$ & $30.6 \%$ \\
Porcentaje de pobres a partir de línea de indigencia $^{2}$ & $16,4 \%$ \\
Índice de Gini & 0,555 \\
\hline
\end{tabular}

Fuente: Elaboración autores con base en MESEP (2009) y González (s.f.).

Otra alternativa de evaluación de la pobreza es el Índice de Desarrollo Humano, el cual es elaborado por el Programa de Naciones Unidas para el Desarrollo, PNUD; este índice compuesto se estructura con base en indicadores de esperanza de vida, niveles educativos, indicadores de ingresos de los hogares. Con este índice se busca obtener un mejor diagnóstico de la pobreza a escala mundial con un indicador que permite la comparación entre países.

Finalmente, en años recientes se ha difundido el índice de calidad de vida, el cual combina, en una sola medida, las variables del potencial de acceso a bienes, tales como características físicas de la vivienda, posibilidades de acceso a servicios públicos, medición del capital humano presente y potencial, educación de los mayores de 12 años, posibilidades de acceso de niños y jóvenes a la educación y composición del hogar.

\section{Una aproximación al Impuesto al Valor Agregado, IVA}

De acuerdo con Alonso, Cantera y Orozco (2006, p. 16), el Impuesto sobre el Valor Agregado IVA grava el consumo de bienes y servicios en Colombia. Se aplica en las etapas de los procesos donde se agrega valor al bien o al servicio, pero es cobrado en última instancia y en su totalidad a los compradores finales. Se calcula normalmente sobre el precio del bien o servicio, incluido cualquier otro impuesto sobre el producto. 
El IVA es un impuesto deducible, pues los productores no deben pagar al gobierno el monto completo que es cobrado a los consumidores, sino que pueden deducir el impuesto que deben pagar por sus propias compras de bienes y servicios destinadas al consumo intermedio o la formación de capital fijo.

El Impuesto al Valor Agregado es un impuesto indirecto, esto quiere decir que se "gravan hechos aislados, generalmente asociados con el gasto o consumo que hacen los individuos a partir de su riqueza o de su renta, pero sin identificarla" (Fino y Vasco, 1999, p. 62); éste último aspecto quiere decir que los impuestos indirectos no consultan la capacidad de pago del contribuyente.

De acuerdo con Fino y Vasco, el IVA "es un gravamen que recae sobre las diferentes etapas del ciclo económico, esto es, importación, producción, distribución y comercialización de bienes corporales muebles, prestación de servicios y en la venta de activos fijos" (1999, p. 201).

De acuerdo con los principales criterios de clasificación de los impuestos, el IVA cumple con las siguientes características:

- Es un impuesto real $\mathbf{l}^{7}$ ya que grava un hecho económico sin consultar la situación personal de quien lo ejecuta.

- General ${ }^{8}$, ya que recae sobre todas las personas o entes, sin distinción.

- Proporcional ${ }^{9}$, dado que presenta una tarifa general sin discriminar por rangos de acuerdo con el hecho generador del impuesto.

7 La otra categoría que existe es personal, donde se clasifican los impuestos que gravan al sujeto de acuerdo con su capacidad de pago.

8 En contraposición a los especiales, que solo afectan a determinado tipo de personas.

9 De la misma forma existen impuestos de suma fija, cuando el valor a pagar es el mismo, independiente de la base gravable, e impuestos progresivos, en los cuales, a mayor base gravable, se aplica mayor tarifa. 
- Nacional ${ }^{10}$, pues es administrado por la Dirección de Impuestos y Aduanas Nacionales, DIAN.

- Impuesto sobre el gasto ${ }^{11}$, ya que grava transacciones efectivas de consumo.

- Impuesto ordinario ${ }^{12}$, es recaudo de forma permanente.

- Regresivo, característica que ya se había mencionado con anterioridad y tiene relación con que el impuesto no tiene en cuenta la capacidad de pago del contribuyente.

Esta última característica adquiere especial importancia en el análisis, ya que tiene una relación estrecha con el tema de pobreza; así, según Hernández,

Si la equidad es deseable en lo social, y si el Estado grava en menor proporción a los contribuyentes de menores recursos y el gasto está dirigido en mayor proporción a ellos, se dice que la estructura tributaria es progresiva. Al contrario, el esquema es regresivo si los ciudadanos con menor dotación de factores pagan mayores tributos y reciben menores beneficios del gasto que los que poseen mejor dotación de factores (2005, p. 24).

De tal forma que la progresividad tiene directa relación con el tema de equidad, con lo social y por lo tanto con la pobreza, aunque se debe considerar que la evaluación se debe hacer a partir de los impuestos, pero complementándolo con el gasto social.

En términos generales, de acuerdo con Jaramillo y Tovar, "el impuesto al valor agregado es una versión de la tributación por el lado del consumo, cuyo diseño incorpora resultados de la teoría tributaria y de la práctica administrativa" (2007, p. 3).

En este sentido, los autores señalan:

10 Existen otros, como los departamentales y municipales.

11 También existen impuestos sobre la renta y sobre el capital.

12 Los extraordinarios son ocasionales y dependen de alguna situación económica o social muy particular. 
El IVA es una manera de gravar los bienes finales sin tener que identificar el momento en la cadena productiva en que se llega a ellos. La idea es gravar solamente el valor agregado en cada etapa productiva, de manera que el precio final al consumidor resulte ser equivalente al impuesto a las ventas sobre bienes finales (íbid., p. 5).

\subsection{IVA y pobreza}

En términos generales, el presente artículo describe la relación de la evolución del IVA con la pobreza en Colombia; ya se han ofrecido elementos para comprender el carácter de esta relación, por ejemplo, se ha señalado que el IVA no consulta la capacidad económica de los agentes.

De acuerdo con la CGR:

Un hogar de nivel superior de la escala de ingresos paga, como proporción de ingreso por concepto de IVA, dos veces lo que paga un hogar del nivel inferior, mientras que su ingreso promedio por hogar es aproximadamente 17 veces el de un hogar de bajos ingresos (1997, p. 65).

\subsection{Modalidades del Impuesto al Valor Agregado}

A pesar de la simpleza del impuesto, éste adquiere diversas formas en las que puede ser cobrado y gestionado. Una primera clasificación se da en términos del conjunto de bienes que grava el impuesto: en algunos países, el impuesto grava un conjunto de bienes específicos; en otros, el IVA se aplica a la generalidad de los productos, y en este sentido pueden crearse un conjunto de exenciones puntuales. En el caso colombiano, el IVA se acoge a la segunda clase, es decir, grava la generalidad de los bienes y servicios, aunque presenta algunas tarifas especiales y algunos productos no gravados: aquellos que son denominados como de la canasta familiar básica.

Otra forma de clasificar el impuesto está relacionada con las etapas del proceso productivo en las cuales se aplica el gravamen. Así, existen formas 
de IVA que solo afectan una de las etapas de dicho proceso (o monofásico); de igual forma, también se estructura el impuesto, de tal manera que grave todas las etapas productivas (o plurifásico). En Colombia, el IVA grava todas las etapas del proceso productivo; en cada fase, el valor del impuesto pagado se calcula sobre el valor que se le agregó al producto después de la anterior etapa. Lo que garantiza que se grave el valor agregado y no el consumo es la posibilidad de que el comprador descuente ese valor en la declaración, sistema que se conoce también como IVA en cascada.

\subsection{Ventajas en el cobro del IVA}

A continuación se presentan algunas de las ventajas del IVA con el fin de identificar los aspectos más relevantes que concurren en el impuesto. Plazas (1998, p. 47) menciona las siguientes:

1. "Permite un tratamiento equitativo entre las exportaciones y las importaciones, dado que permite un análisis detallado de éstas.

2. Es elástico con respecto a los ingresos que generan la actividad económica, ya que grava todas las etapas del ciclo productivo.

3. No incide en la integración de las empresas, ni estimula por sí solo la concentración de la riqueza; es lo que Giraldo llama neutral.

4. Ya que se presenta en la totalidad de las etapas del ciclo productivo, recae sobre todo el valor agregado, lo que amplía la base y, por ende, el recaudo de ingresos tributarios.

5. Contribuye al control fiscal frente a la evasión, ya que facilita la utilización de la información cruzada.

6. En su modalidad plurifásica es más complejo elaborar mecanismos de evasión frente a dicho impuesto, es decir, como se presenta en cada una de las etapas se dificulta su evasión, ya que se presenta el impuesto por parte del contribuyente de la etapa anterior y de la siguiente, lo cual se evidenciaría en las declaraciones tributarias". 
Fino y Vasco (1999, p. 204) adicionan las siguientes características:

1. "Es necesario, dadas las crecientes necesidades estatales en materia de recaudo de impuestos.

2. Grava un mayor número de personas que el impuesto de renta.

3. Permite contrarrestar los efectos regresivos, siempre y cuando tenga en cuenta el principio de equidad. Aspecto bastante discutible, ya que existe una tarifa general, la cual aplica cada vez a más productos, inclusive de la canasta familiar.

4. Contribuye a la eficiencia y eficacia en los procesos de recaudo y fiscalización" Jaramillo y Tovar (2007, p. 3) añaden:

1. "Si se presenta evasión no se pierde la totalidad del recaudo, ya que se realiza en todas las etapas".

Las desventajas son claramente identificables a partir de las características mismas del impuesto: por un lado, impacta el consumo, ya que se tiene que destinar una proporción de éste para el pago del impuesto; adicionalmente, tiene efectos sobre la equidad y la progresividad, al gravar la generalidad de las personas y no consultar la capacidad de pago, lo cual tiene efectos sociales importantes.

De acuerdo con Vasco, "el IVA tiene efectos deflacionarios porque castiga la parte de los ingresos que se destina al consumo, lo que incita a consumir menos, lo cual va en contra de los mismos ingresos fiscales" (2006, p. 72). Lo anterior apoya la idea de que el IVA afecta el consumo. Vasco (íbid.) añade que muchos de los bienes de la canasta familiar están gravados con dicho impuesto, lo que sumado a lo anterior supone que el IVA afecta el consumo de bienes básicos.

En este sentido, Silva indica que

Los teóricos del IVA han señalado que el IVA perfecto sería aquel que tenga un efecto neutro en la economía. Para efectos de lograr este objetivo, estos 
académicos han planteado la existencia de una tarifa única de la mano con una base gravable, que no deje nada por fuera o nada sin gravarse. Si bien, por un lado, un IVA con estas características lograría el efecto de la neutralidad, no conseguiría resolver quizá el mayor problema de este tipo de tributos: la regresividad (2008, p. 9).

Ésta sería la dificultad más notoria del IVA, ya que conduce a condiciones inequitativas dentro de la población.

Para finalizar, es necesario señalar que, en los últimos años, el IVA ha sufrido un amplio número de cambios; estos se presentan en la Tabla 3.

Tabla 3. Cambios que ha presentado el IVA en Colombia en el periodo comprendido entre 1984 y 2009

\begin{tabular}{|c|c|c|}
\hline Periodo & Cambio en tarifas & Otros cambios \\
\hline 1984-1990 & $\begin{array}{l}\text { Tarifas del } 10 \% \\
\text { (tarifa general), } 15 \% \text {, } \\
20 \% \text { y } 35 \% .\end{array}$ & $\begin{array}{l}\text { Surge el concepto de valor agregado, es decir, se } \\
\text { grava en todas las etapas: producción, distribu- } \\
\text { ción y comercialización. }\end{array}$ \\
\hline 1991-1992 & $\begin{array}{l}\text { Se incrementa la } \\
\text { tarifa general del } 10 \% \\
\text { al } 12 \% \text {. }\end{array}$ & $\begin{array}{l}\text { Se amplía el impuesto a algunos servicios y se } \\
\text { precisan los impuestos descontables. }\end{array}$ \\
\hline 1992-1995 & $\begin{array}{l}\text { Se incrementa la } \\
\text { tarifa general del } 12 \% \\
\text { al } 14 \% \text {. }\end{array}$ & Se empieza a penalizar la evasión. \\
\hline 1996-1998 & $\begin{array}{l}\text { Se establece la tarifa } \\
\text { general en } 16 \% \text {. }\end{array}$ & $\begin{array}{l}\text { Se crea la retención en la fuente a título de IVA } \\
\text { y se amplían las tarifas diferenciales. }\end{array}$ \\
\hline $1999-2000$ & $\begin{array}{l}\text { Se disminuye la tarifa } \\
\text { general al } 15 \% .\end{array}$ & \\
\hline 2001-2002 & $\begin{array}{l}\text { Se vuelve a incremen- } \\
\text { tar la tarifa general al } \\
16 \% \text {. }\end{array}$ & Se establece la retención del impuesto en $75 \%$. \\
\hline 2002-2003 & & Incremento en tarifas diferenciales. \\
\hline 2004-2006 & & Modificación en bienes excluidos. \\
\hline 2006-2009 & & Se crea la tarifa diferencial del $1,6 \%$. \\
\hline
\end{tabular}

Fuente: Elaboración propia con base en Fino y Vasco, 2001, p. 205, Ley 488 de 1998, Ley 633 de 2000, Ley 788 de 2002, Ley 863 de 2003 y Ley 1111 de 2006. 


\section{Medición del impacto de los cambios del Impuesto al Valor Agregado IVA sobre la pobreza en Colombia en el periodo 1999 - 2009}

Lo analizado con anterioridad es determinante en la caracterización del IVA, con el fin de establecer cómo afecta la evolución de la pobreza; en realidad, el problema es la forma en que los impuestos se establecen en la estructura fiscal. En palabras de Fino y Vasco:

Si todos los impuestos fueran directos, quedarín grandes núcleos de población sin tributar, pero si todos fueran indirectos, la carga fiscal sería únicamente sobre las clases menos favorecidas, lo que atentaría sobre varios principios tributarios; especialmente: justicia, igualdad y equidad (1999, p. 201).

\subsection{Metodología}

Analizar el efecto del IVA en la pobreza resulta pertinente para identificar la influencia de las decisiones de política pública en el aumento o detrimento del bienestar de la población, entendida ésta última como la disminución del ingreso que destina para el consumo. Si bien la pobreza es entendida como las variaciones del nivel de ingreso de la población, para el trabajo es necesario tener presentes variables económicas como el Producto Interno Bruto, el coeficiente de Gini y los tributos.

El análisis econométrico parte del modelo de Mincer (1974), el cual desarrolla un clásico estudio econométrico de los retornos al entrenamiento laboral ${ }^{13}$. Parte del supuesto que el entrenamiento es general y encuentra que los retornos a la experiencia son positivos, pero decrecientes ante au-

13 A modo de síntesis, Micer plantea que los grados académicos son un modo efectivo utilizado por las empresas para identificar a los trabajadores altamente calificados. De hecho, quienes tienen un mayor grado de educación poseen mayores habilidades y entrenamiento. De acuerdo con esta hipótesis, el grado académico es un pasaporte para conseguir trabajos mejor remunerados, en los cuales las posibilidades de entrenamiento y promoción son mayores. 
mentos en la experiencia. También analiza la interacción entre experiencia y escolaridad, concluyendo que los retornos a la experiencia disminuyen con incrementos en escolaridad y años de experiencia.

El modelo considera la inversión en educación como si se tratara de una inversión en un bien físico, y capitaliza el ingreso que de ella se deriva según los años de educación del individuo y la tasa de rendimiento que proporciona cada año de educación. Así, para el primer año, la tasa de rendimiento es igual a la diferencia de ingresos percibidos planteada como:

$$
R 1=\frac{(Y t-Y o)}{Y 0} \quad[1]
$$

Donde Yt es el ingreso obtenido después del primer año.

$$
R 2=\frac{(Y t 2-Y 1)}{Y 1}
$$

Donde Y2 es igual al ingreso después del segundo año despejando la ecuación 2.

$$
Y 2=Y t(1+r 2)=Y o(1+R 1)(1+R 2)
$$

Del mismo modo, se obtendrá el valor del ingreso para s años de educación, como lo muestra la siguiente ecuación:

$$
Y s=Y_{o}(1+r 2)=Y_{o}(1+R 1)(1+R 2) \ldots \ldots . .(1+R s) \quad[4]
$$

Bajo el supuesto de una tasa de rendimiento constante para todos los años de educación, es posible redefinirla como:

$$
\ln Y s=\ln Y o+r s+u \quad[5]
$$

Donde el logaritmo natural del ingreso con s años de educación está en función del logaritmo natural del ingreso en ausencia de educación, más la tasa de retorno o de rendimiento de la educación multiplicado por los años de educación más el término residual. 
Mincer incorpora la experiencia del trabajo, redefiniendo la ecuación como:

$$
\ln \mathrm{Yi}=\ln \mathrm{Yo}+\beta_{1} S_{1}+\beta_{2} \mathrm{KiXi}+\mathrm{Ui} \quad[5]
$$

Donde $\beta_{1}$ representa la tasa de rendimiento de la inversión en educación, $\beta_{2}$ la tasa de rendimiento de la experiencia, Ki la proporción del trabajo dedicado y Xi presenta el número de años de permanencia del trabajador en el mercado laboral.

\section{Agregado del modelo}

Mincer determina el nivel de ingresos de la población con respecto al trabajo realizado, lo cual nos permite medir el impacto con respecto a los impuestos.

$$
\mathrm{P}=\ln \mathrm{Y}+\beta \_1 \mathrm{G}+\beta \_2 \gamma \mathrm{T}+\varepsilon
$$

Donde $P$ es la pobreza, entendida como LN del ingreso, $\beta_{1} G$ ingreso total de la población como participación en la economía PIB $\beta_{2} \gamma$ T y la tasa de impacto del impuesto del IVA. La $\varepsilon$ como variable dummy se realizó con el objetivo de explicar los diferenciales del impuesto de acuerdo con las diferentes categorías existentes.

Los datos para el modelo tienen fuente de información primaria suministrados por la DIAN, el Banco de la República y el Departamento Nacional de Planeación.

\subsection{Resultados}

Los cambios en el IVA contribuyeron a reducir los ingresos de la población e incrementar la pobreza, de acuerdo con la ecuación de Mincer. Una explicación puede ser por un ajuste del mercado laboral por cantidades, en contra de trabajadores no calificados, que se traduce en un aumento de los ingresos laborales relativos entre calificados y no calificados y, con ellos, la mayor rentabilidad de la educación. En cuanto al impuesto, los cambios 
en la distribución del ingreso confirman el aumento de la pobreza. En los anexos 2, 3 y 4 podemos encontrar los resultados del modelo por cada una de las variables, donde se resaltan los efectos del IVA en las demás variables. Los impactos en el IVA de 5 puntos tienen su incidencia en el ingreso en $3,8 \%$. Un impacto en el IVA de 7 puntos tiene un impacto en el ingreso en 3,3\%. Un cambio en el IVA de 0,1 puntos impacta el ingreso en 2,7\%.

Cambios generalizados en el cobro del IVA generan un impacto negativo en el ingreso de la población, aumentando la pobreza, si consideramos que la población de menos ingresos se ve afectada por aumentos del Impuesto al Valor Agregado.

Estos determinantes afectan el comportamiento económico, en el cual una decisión de política pública en pro de mejorar los ingresos del gobierno incrementa la pobreza en términos de referencia del ingreso.

Tabla 4. Variación de la pobreza en Colombia 2003-2009

\begin{tabular}{llllll}
\hline Ingreso & 2003 & 2004 & 2005 & 2008 & 2009 \\
Nacional & 0,078 & 0,054 & 0,068 & 0,029 & 0,034 \\
Cabecera & 0,076 & 0,053 & 0,067 & 0,028 & 0,035 \\
13 áreas & 0,075 & 0,054 & 0,067 & 0,027 & 0,037 \\
Resto & 0,079 & 0,054 & 0,065 & 0,029 & 0,031 \\
\hline
\end{tabular}

Fuente: elaboración propia a partir de los datos del Departamento Nacional de Planeación.

Los cambios en el nivel laboral de la población, por lo tanto en el nivel de los ingresos, e incrementos en los tributos, son los aspectos que más inciden en la pobreza. Es importante encaminar esfuerzos a mejorar el comportamiento del mercado laboral, en particular, disminuir el desempleo sin afectar el nivel de tributación. 
Tabla 5. Variación del ingreso 2000-2006 con un incremento del IVA en 5 puntos Miles de millones de pesos

\begin{tabular}{lcc}
\hline & INGRESO & $\begin{array}{c}\text { VARIACIÓN INGRESO CON } \\
\text { INCREMENTO DEL IVA 5 PUNTOS }\end{array}$ \\
\hline 2000 & 196.373 .851 & $186.555 .158,5$ \\
2001 & 213.582 .653 & $202.903 .520,4$ \\
2002 & 232.933 .484 & $221.286 .809,8$ \\
2003 & 263.887 .767 & $250.693 .378,7$ \\
2004 & 299.066 .590 & $284.113 .260,5$ \\
2005 & 335.546 .939 & $318.769 .592,1$ \\
2006 & 383.322 .872 & $364.156 .728,4$ \\
\hline
\end{tabular}

Fuente: cálculos propios, datos DANE, DNP, DIAN.

El incremento del impuesto del IVA en cinco puntos disminuye los ingresos en la economía, afectando la distribución de estos e influenciando la formación de la desigualdad y la pobreza en la población. Para el año 2000, la variación afecta los ingresos en aproximadamente nueve mil millones; para 2006, en diecinueve mil millones aproximadamente.

\section{Conclusiones}

Los impuestos son un aspecto fundamental en el entorno económico de los países, por lo cual se deben tener en cuenta al momento de evaluar su impacto sobre la población. Dentro de los principios de la tributación, los principales son la equidad, la cual busca que los contribuyentes aporten tributos de acuerdo con sus capacidades económicas; Macías y Cortés (2004) apoyan la idea mencionando que "los tributos deben gravar igual a quienes tienen la misma capacidad contributiva; allí deben estar ausentes las excepciones que se hacen sobre algunos tipos de contribuyentes, especialmente por la localización de sus actividades y por las actividades mismas".

Stiglitz (2003, p. 483) plantea que existen cinco características deseables dentro de un sistema tributario, las cuales describe de la siguiente manera: 
1. Eficiencia económica: no debe interferir en la asignación eficiente de recursos.

2. Sencillez administrativa: debe ser fácil y relativamente barato de administrar.

3. Flexibilidad: debe ser capaz de responder fácilmente (en algunos casos automáticamente) a los cambios de las circunstancias económicas.

4. Responsabilidad política: debe diseñarse de tal forma que cada individuo pueda averiguar qué está pagando y saber en qué medida el sistema refleja sus preferencias.

5. Justicia: debe ser justo en su manera de tratar a los diferentes individuos.

Otro tema fundamental dentro de la economía son las condiciones sociales de la población, dentro de las cuales se tiene en cuenta como factor primordial la evaluación de la pobreza, concepto que ha sido cambiante a lo largo de la historia pero que, sin embargo, ha sido considerada por muchos economistas en distintos periodos.El vínculo entre impuestos y pobreza ha sido considerado recientemente; economistas clásicos trataron dichos temas pero no buscando un vínculo entre los dos; para los mercantilistas, el interés en el tema de impuestos era incentivar el comercio exterior; Adam Smith evaluaba cómo los impuestos distorsionaban lo que él llamaba la "mano invisible", y posteriormente se fueron desarrollando diferentes conceptos, así como distintas preocupaciones en las cuales se trata de establecer la incidencia que tienen los impuestos sobre las condiciones sociales de la población, específicamente de la pobreza y la distribución del ingreso.

El presente trabajo evaluó la incidencia que tiene el IVA, como un impuesto representativo de los impuestos indirectos sobre la pobreza en Colombia, en el periodo comprendido entre el año 1999 y el 2009, llegando a la conclusión de que cualquier cambio porcentual en el IVA tiene una relación directa sobre los niveles de pobreza, de tal forma que se logró confirmar que los impuestos indirectos, específicamente el IVA, tienen un impacto sobre la pobreza, ya que afectan el consumo y son impuestos regresivos al no consultar la capacidad de pago de los contribuyentes, por lo tanto éste es un elemento de política sobre el cual se podría incidir para reducir los niveles de pobreza en Colombia. 
En el modelo se observa que, en general, el IVA impacta sobre el nivel de ingresos de la población y, por ende, en la pobreza de la misma; se observa que un incremento del IVA en 5 puntos disminuye el ingreso en $3,8 \%$, mientras que un aumento de 7 puntos tiene un impacto en el ingreso en 3,3\%, y que un cambio de 0,1 puntos impacta el ingreso en 2,7 \%, con lo cual se observa que, en los casos analizados, hay impacto directo sobre el nivel de ingreso siempre que se incremente el IVA porcentualmente, lo cual es prueba empírica de que los impuestos indirectos afectan el ingreso de los contribuyentes y por lo tanto la pobreza.

\section{Referencias bibliográficas}

Alonso, Cantera y Orozco (2006). Sector público y déficit fiscal. Apuntes de economía. Universidad ICESI.

Bustelo, P. (1999). Teorías contemporáneas del desarrollo económico. Madrid: Editorial Síntesis.

Clavijo, S. (2005). Tributación, equidad y eficiencia en Colombia: Guía para salir de un Sistema Tributario Amalgamado. Banco de la República.

Congreso de la República de Colombia. Ley 1111 (2006). Por la cual se modifica el estatuto tributario de los impuestos administrados por la dirección de impuestos $y$ aduanas nacionales.

. Ley 863 (2003). Por la cual se establecen normas tributarias, aduaneras, fiscales $y$ de control para estimular el crecimiento económico y el saneamiento de las finanzas públicas.

. Ley 788 (2002). Por la cual se expiden normas en materia tributaria y penal del orden nacional y territorial; $y$ se dictan otras disposiciones.

. Ley 633 (2000). Por la cual se expiden normas en materia tributaria, se dictan disposiciones sobre el tratamiento a los fondos obligatorios para la vivienda de interés social y se introducen normas para fortalecer las finanzas de la Rama Judicial.

. Ley 488 (1998). Por la cual se expiden normas en materia tributaria y se dictan otras disposiciones fiscales de las Entidades Territoriales. 
Contraloría General de la República (1997). "Impacto de la tributación indirecta sobre la equidad”. La Situación de las Finanzas Públicas (Informe Anual de la CGR al Congreso).

DIAN Dirección de Impuestos y Aduanas Nacionales (2011). Estatuto tributario. . Recaudo Anual por tipo de Impuestos 1970-2011 p.[En línea]. http:// www.dian.gov.co/dian/14cifrasgestion.nsf/pages/Recaudo_tributos_ dian?OpenDocument [2011, marzo, 31].

Fino, G. y Vasco R. (1999). Elementos básicos de la tributación en Colombia. Medellín: Centro Interamericano Jurídico - Financiero.

Franco, R. (1996). Los paradigmas de la política social en América Latina. [En línea]. http://www.eclac.org/publicaciones/xml/6/12726/LCR_1625_Paradigmas. pdf [2010, marzo, 31].

Giraldo, C. (2001). Finanzas Públicas en América Latina: La economía política. $1^{\mathrm{a}}$ Edición. Desde Abajo.

González, A. (1968). Impuestos y desarrollo económico de Colombia. Tercer Mundo. González, F., Calderón, V. (2002). Las reformas tributarias en Colombia durante el siglo XX (II). [En línea]._http://www.dnp.gov.co/archivos/documentos/ DEE_Boletines_Divulgacion_Economica/Boletin\%20No_9_Reforma_ Tributaria\%20II.pdf [2009, octubre, 3].

González, J. (1995). "El IVA: Impuesto Regresivo”. Cien Días, Vol. 7, No. 31. . (s.f.). Más inversión, más pobreza y más desigualdad. [En línea]. http:// www.cinep.org.co/node/988 [2011, junio, 9].

Hernández, I. (2005). Teoría y política fiscal. Bogotá: Universidad Externado de Colombia.

Jaramillo, C.; Tovar J. (2007). Reflexiones sobre la teoría y la práctica del IVA en Colombia. Documentos CEDE No. 7. Universidad de los Andes. pp. 1-22.

Landreth, H. (1998). Historia del pensamiento económico. Compañía editorial continental. México.

Larrañaga O. (2007). La medición de la pobreza en dimensiones distintas al ingreso. Serie estudios estadísticos y prospectivos. CEPAL.

Macías, H., Cortés, J. (2004). Disminuir la tarifa general de IVA en Colombia aumentaría el recaudo tributario. Revista Semestre Económico, No. 13. Universidad de Medellín.

Macon J., Pavesi P. (1973). Un impuesto al valor agregado para Argentina. El Ateneo Editorial. 
Marx, K. (1946). El Capital, I. Crítica de la Economía Política. Fondo de Cultura Económica, México D.F.

Misión para el Empalme de las Series de Empleo, Pobreza y Desigualdad (2009). Indicadores de pobreza, indigencia y desigualdad 2009. [En línea]. http://www. dnp.gov.co/PortalWeb/LinkClick.aspx?fileticket=1gcbiDNDZ\%2F4\%3D\&tab id=337 [2011, junio, 7].

Musgrave, Musgrave (1992). Hacienda Pública teórica y aplicada. Quinta edición. Mc Graw Hill.

Núñez, J. (2009). Incidencia del gasto público social en la distribución del ingreso, la pobreza y la indigencia. Departamento Nacional de Planeación. [En línea]. http://econpapers.repec.org/paper/col000118/006448.htm [2009, octubre, 3].

Ortiz, J; Ortiz, E; Cárdenas, P. (2004). Revisión del debate sobre la pobreza orientado al diseño de políticas. Análisis económico,Vol. XIX, número 042, Universidad Autónoma Metropolitana, México.

Páez, P. (2003). Consumo, reformas tributarias y deuda externa. Revista Economía y Desarrollo No. 2.

Pardo, E. (2000). La pobreza en Smith y Ricardo. Revista de Economía Institucional. Bogotá: Universidad Externado de Colombia.

Parra, J. (1995). Incidencia distributiva del IVA en un modelo del ciclo de vida. Bogotá: Departamento Nacional de Planeación.

Pesenti, A. (1960). Lecciones de Economía Política.

Plazas, M. (1998). El Impuesto sobre el Valor Agregado IVA. Bogotá: Temis.

Ramírez, C. (2002). Pobreza en Colombia: Tipos de medición y evolución de políticas entre los años 1950 y 2000. Revista Estudios Gerenciales. Universidad ICESI. República de Colombia. Constitución Política de Colombia. 1991.

Ricardo, D. (1993). Principios de Economía Política y tributación. Fondo de Cultura económica. México D.F.

Roll, E. (1994). Historia de las doctrinas económicas. Fondo de Cultura Económica. México D.F.

Sánchez, F. Impuestos y reformas tributarias en Colombia: 1980-2003.

Sarmiento, L. (1998) Focalizar o universalizar, un falso dilema. Cuadernos de economía, No. 29. Universidad Nacional de Colombia.

Sen, A. (2002). La desigualdad económica. México: Fondo de Cultura Económica. . (1989). Sobre ética y economía. Madrid: Alianza. 
(1983). Poor relatively speaking. Oxford Economic Papers, New series, Vol. 35, No.2 (jul, 1983). [En línea]. http://www.jstor.org/stable/2662642[2010, mayo, 21].

Serrano D. (2001). El concepto de pobreza, su medición y la relación con los problemas del medio ambiente. Manizales: Universidad de Caldas.

Silva A. (2005). América Latina: los rostros de la pobreza y sus causas determinantes. Revista investigación y reflexión. Universidad Militar Nueva Granada.

Silva R. (2008). Un IVA regresivo para América Latina: cambiando el esquema tributario, de regresivo e injusto a progresivo y socialmente responsable. [En línea]. http://www.cesla.com/analisis/archivos/Premioensayo.pdf [2010, mayo, 21].

Sottoli, S. (2002). La política social en América Latina: Diez dimensiones para el análisis y el diseño de políticas. [En línea]. http://redalyc.uaemex.mx/redalyc/ pdf/112/11203410.pdf. [2009, octubre, 3].

Steiner, R., Soto, C. (1998). IVA: Productividad, evasión y progresividad. Bogotá: Fedesarrollo.

Stiglitz, J. (2003). Economía del sector público. Tercera edición. Antoni Bosch editor.

Vasco, R. (2006). El impuesto sobre las ventas IVA. Medellín: Centro Interamericano Jurídico - Financiero.

Ziccardi, A. (1999). Pobreza y políticas sociales. Revista Mexicana de Sociología. Vol. 61, No. (4). 


\section{Anexos}

Anexo 1. Recaudo del IVA como porcentaje del total de los impuestos nacionales entre 1990 y 2009

\begin{tabular}{ll}
\hline Año & $\begin{array}{c}\text { Porcentaje del recaudo del IVA en el total de } \\
\text { impuestos nacionales }\end{array}$ \\
\hline 1990 & $31,63 \%$ \\
1991 & $32,59 \%$ \\
1992 & $37,70 \%$ \\
1993 & $43,99 \%$ \\
1994 & $44,71 \%$ \\
1995 & $44,78 \%$ \\
1996 & $49,50 \%$ \\
1997 & $45,84 \%$ \\
1998 & $46,03 \%$ \\
1999 & $43,01 \%$ \\
2000 & $44,22 \%$ \\
2001 & $42,12 \%$ \\
2002 & $41,51 \%$ \\
2003 & $43,60 \%$ \\
2004 & $42,72 \%$ \\
2005 & $42,35 \%$ \\
2006 & $42,97 \%$ \\
2007 & $43,41 \%$ \\
\hline
\end{tabular}

Fuente: Elaboración autores a partir de los datos de DIAN (2011). 
Anexo 2. Variación del ingreso 2000 - 2006 con un incremento del IVA en 5 puntos

\begin{tabular}{lcc}
\hline & INGRESO & $\begin{array}{c}\text { \% VARIACIÓN INGRESO } \\
\text { CON INCREMENTO DEL IVA 5 PUNTOS }\end{array}$ \\
\hline 2000 & 196.373 .851 & 186555158,5 \\
2001 & 213.582 .653 & 202903520,4 \\
2002 & 232.933 .484 & 221286809,8 \\
2003 & 263.887 .767 & 250693378,7 \\
2004 & 299.066 .590 & 284113260,5 \\
2005 & 335.546 .939 & 318769592,1 \\
2006 & 383.322 .872 & 364156728,4 \\
\hline
\end{tabular}

Fuente: Elaboración autores a partir de los datos de DIAN (2011).

Anexo 3. Resultados del modelo con IVA

\begin{tabular}{cc}
\hline \multicolumn{2}{c}{ Standard errors in () \& t- statistics i... } \\
\hline & \multicolumn{1}{c}{ IVA } \\
\hline IVA (-1) & -032195 \\
& $(0,09315)$ \\
& $-0,34562$ \\
IVA (-2) & $-0,003761$ \\
& $(0,09318)$ \\
C & $-0,04037$ \\
& 1866276 \\
& $(375971)$ \\
R-Squared & 4,96388 \\
Adj. R-Squared & 0,001045 \\
Sum Sq Resids & $-0,016328$ \\
S.E. equation & $1,14 \mathrm{E}+15$ \\
F-statistic & 3155219 \\
Log likelihood & 0,060117 \\
Akaike AIC & $-1931,734$ \\
Schwarz SC & 32,79211 \\
Mean dependent & 32,86255 \\
S.D. dependent & 1802125 \\
\hline
\end{tabular}


Anexo 4. Resultados del modelo con PIB

\begin{tabular}{lc}
\hline Standard errors in () \& t- statistics i... \\
\hline \multicolumn{1}{c}{ PIB } \\
\hline PIB (-1) & 0,137015 \\
& $(0,09292)$ \\
& 1,47454 \\
& $-0,084019$ \\
& $(0,09283)$ \\
\multicolumn{1}{c}{ C } & $-0,90509$ \\
& 9587756 \\
& $(12.7326)$ \\
& 7,53009 \\
\hline R-Squared & 0,022927 \\
Adj. R-Squared & 0,005934 \\
Sum Sq Resids & 106335,1 \\
S.E. equation & 30,40811 \\
F-statistic & 1,349212 \\
Log likelihood & $-568,8510$ \\
Akaike AIC & 9,692390 \\
Schwarz SC & 9,762832 \\
Mean dependent & 101,2496 \\
S.D. dependent & 30,49873 \\
\hline
\end{tabular}


Anexo 5. Resultados del modelo con ingreso

\begin{tabular}{lc}
\hline \multicolumn{2}{c}{ Standard errors in () \& t- statistics i... } \\
\hline INGRESO \\
\hline INGRESO (-1) & $-0,030478$ \\
& $(0,09312)$ \\
& $-0,32371$ \\
INGRESO (-2) & $-0,034253$ \\
& $(0,09306)$ \\
& $-0,36807$ \\
C & 6709775 \\
& $(1311660)$ \\
& 5,11548 \\
\hline R-Squared & 0,002048 \\
Adj. R-Squared & $-0,015308$ \\
Sum Sq Resids & $1,39 \mathrm{E}+16$ \\
S.E. equation & 10980540 \\
F-statistic & 0,118012 \\
Log likelihood & $-2078,888$ \\
Akaike AIC & 35,28624 \\
Schwarz SC & 35,35668 \\
Mean dependent & 6304484 \\
S.D. dependent & 10897450 \\
\hline & \\
& \\
&
\end{tabular}


Anexo 6. Comportamiento del ingreso

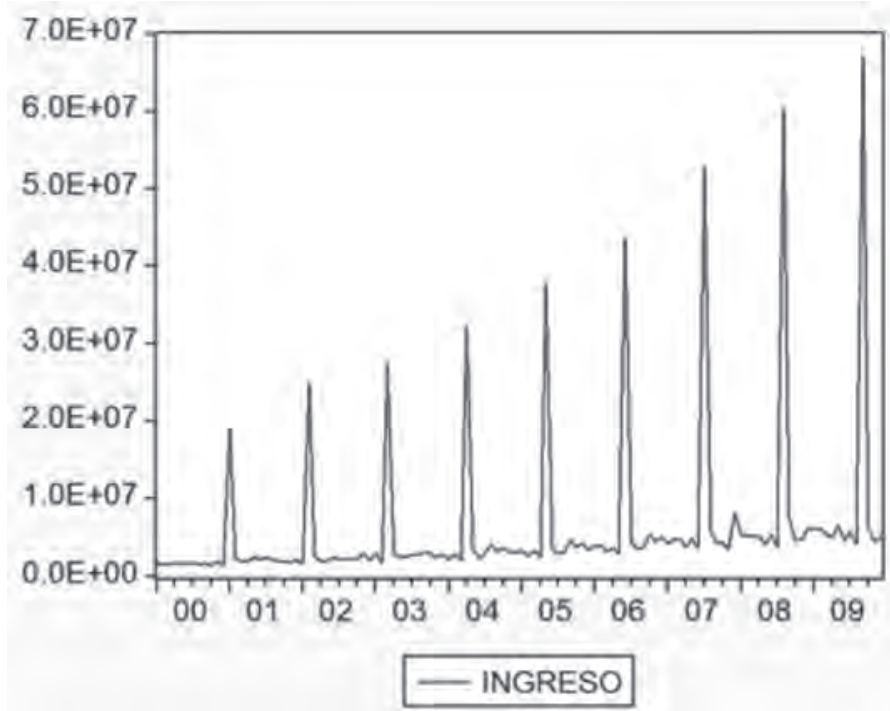

Anexo 7. Comportamiento del IVA

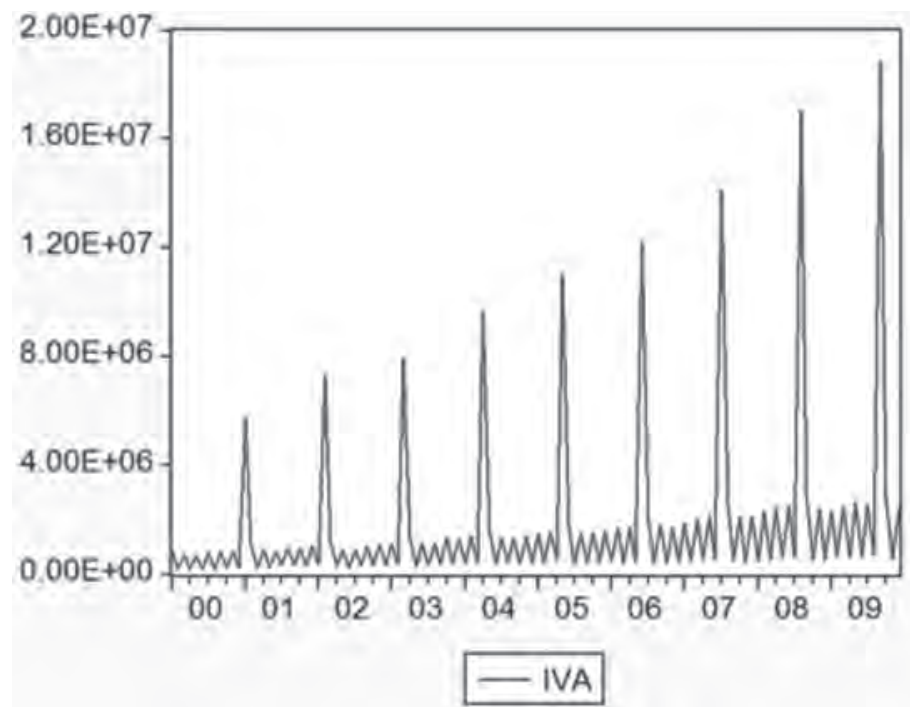

ISSN: 0124-5805, Revista Activos, N. ${ }^{\circ} 20$, enero-junio de 2013, pp. 183-227 
Anexo 8. Comportamiento del PIB

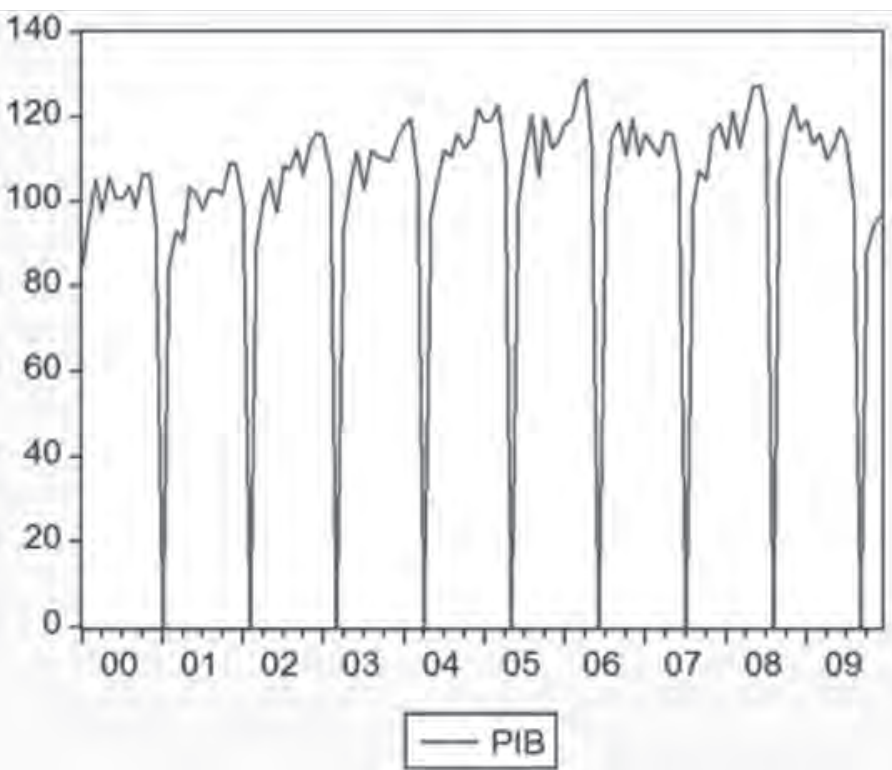

Anexo 9. Comportamiento variación del ingreso frente a cambios en el IVA en 5 puntos

Series: IVA

Exogenous series: INGRESO

Warming: Critical values assume no exogenous series

Lags interval (in first differences): 1 to 4

Unrestricted Cointegration Rank Test (Trace)

\begin{tabular}{ccccc}
\hline $\begin{array}{c}\text { Hypothesized } \\
\text { No. of } \mathrm{CE}(\mathrm{s})\end{array}$ & Eigenvalue & $\begin{array}{c}\text { Trace } \\
\text { Statistic }\end{array}$ & $\begin{array}{c}\text { 0,07 Critical } \\
\text { Value }\end{array}$ & Prob.** $^{* *}$ \\
\hline None $^{*}$ & 0,783149 & 1.757 .826 & 3,283023 & 0,0000 \\
\hline
\end{tabular}

Trace test indicates 1 cointegrating eqn(s) at the 0,07 level

* denotes rejection of the hypothesis at the 0,07 level

** MacKinnnon-Haug-Michelis (1999) p-values 
Anexo 10. Comportamiento variación del ingreso frente a cambios en el IVA en 7 puntos

Included obsrvations: 115 after adjustments

Trend assumption: Quadratic deterministic trend

Series: IVA

Exogenous series: INGRESO

Warming: Critical values assume no exogenous series

Lags interval (in first differences): 1 to 4

Unrestricted Cointegration Rank Test (Trace)

\begin{tabular}{ccccc}
\hline $\begin{array}{c}\text { Hypothesized No. of } \\
\text { CE(s) }\end{array}$ & Eigenvalue & Trace Statistic & $\begin{array}{c}0,07 \text { Critical } \\
\text { Value }\end{array}$ & Prob. $^{* *}$ \\
\hline None $^{*}$ & 0,783149 & 175.7826 & 2,705545 & 0,0000
\end{tabular}

Trace test indicates 1 cointegrating eqn(s) at the 0,1 level

${ }^{*}$ denotes rejection of the hypothesis at the 0,1 level

**MacKinnnon-Haug-Michelis (1999) p-values 